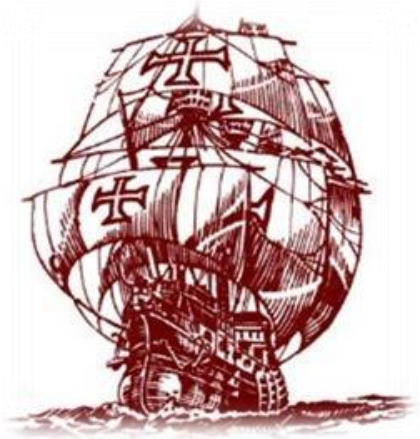

Nau Literária: crítica e teoria de literaturas www.seer.ufrgs.br/nauliteraria ISSN 1981-4526 - PPG-LET-UFRGS - Porto Alegre

Vol. 11 N. 02

Literatura e Guerra

\title{
A INCAPACIDADE DE NARRAR COMO FENÔMENO DE LINGUAGEM E DE SUBJETIVIDADE EM NADA DE NOVO NO FRONT, DE REMAR- QUE
}

\section{PEDRO DOS SANTOS ${ }^{\mathrm{i}}$}

Resumo: O romance de Remarque exemplifica a incapacidade de narrar, nos termos de Benjamin, e seu protagonista possui as características principais do herói romanesco. $\mathrm{O}$ autor responde ao desafio de constituir uma narrativa de guerra, com base numa mimese realista, não naturalista, mas constituída por um relato em primeira pessoa e num tempo presente, em que o real do dizer coincide com o real narrado, na forma descrita pela teoria da enunciação de Émile Benveniste, que liga linguagem e subjetividade. Ao fim da leitura, vemos que nada sobrou da idealização romântica do herói. O ponto de vista do vencido torna o seu pacifismo mais humano; as personagens são retratadas com humanidade, mesmo os inimigos.

Palavras-chave: guerra de trincheiras; guerra na literatura; herói; incapacidade de narrar; subjetividade na linguagem.

Abstract: Remarque's novel exemplifies the incapability of narrating, according to Benjamin, and its protagonist has the main characteristics of novel's hero. The author meets the challenge to make a narrative of war, based on a realistic mimesis, not naturalistic, but consisting of a first-person report in the present tense, in which the reality of saying coincides with the narrated reality, in the way described for Enunciation Theory of Émile Benveniste, which connects language and subjectivity. After reading, we see that nothing was left from romantic idealization of the hero. The viewpoint of the vanquished one makes its pacifism more humane. The characters are portrayed with humanity, even enemies.

Keywords: hero; incapability of narrating; subjectivity in language; trench warfare; war in literature.

Este ensaio apresenta a hipótese de que a incapacidade de narrar, nos termos expostos por Walter Benjamin no artigo intitulado $O$ narrador: considerações sobre a obra de Nikolai Leskov, de 1936, manifesta-se no relato em primeira pessoa de Nada de novo no front. O romance de Erich Maria Remarque, escrito nos primeiros anos do pós-guerra e publicado pela primeira vez em 1929, enfrentou, quase pioneiramente, o desafio de narrar o inenarrável, ao dar tratamento literário, do ponto de vista do vencido, à terrível experiência da derrota alemã na guerra de trincheiras, técnica de combate que caracterizou a Primeira Guerra Mundial (1914-1918).

O relato da experiência da guerra de trincheiras em Nada de novo no front caracteriza-se inicialmente pelo contraste e oposição com a descrição romântica do conflito bélico, enquanto palco de heróis e suas glórias, apresentada no discurso ideológico do regime vigente na Alemanha da época. Esse discurso é reproduzido por agentes diversos, de diferen- 
tes camadas sociais, desde líderes políticos até professores e pais, com o objetivo de incitar e convencer a juventude a participar da guerra ${ }^{1}$ :

Kantorek nos leu tantos discursos nas aulas de ginástica que a nossa turma inteira se dirigiu, sob o seu comando, ao destacamento do bairro e alistou-se. (REMARQUE, 1981, p. 15)

(...) naquela época, até os nossos próprios pais usavam facilmente a palavra "covarde". (idem)

Mas as personagens de Nada de novo no front logo desenvolveram uma visão diferente, mais conectada à realidade. De fato, o que encontraram no front desvaneceu rapidamente o discurso de líderes e conselheiros:

Enquanto eles continuavam a escrever e a falar, víamos os hospitais e os moribundos; enquanto proclamavam que servir o Estado era o mais importante, já sabíamos que o pavor de morrer é mais forte. (...) De súbito, ficamos terrivelmente sós — e, sós, tínhamos de nos livrar de toda esta embrulhada. (REMARQUE, 1981, p. 16)

Os soldados são ensinados a odiar o inimigo enquanto uma ideia. Porém, cedo descobrem que essa ideia se desfaz quando o adversário é abatido, e seu cadáver reassume, tardiamente, o significado de homem:

- Companheiro, não queria matá-lo. (...) antes, você era apenas um pensamento (...) Foi esta abstração que apunhalei. Mas agora, pela primeira vez, vejo que é um ser humano como eu.

(REMARQUE, 1981, p. 179-180)

Em outras situações, a descoberta se dá antes de matar. É quando o inimigo, visto de perto, desarmado e prisioneiro, revela-se em sua humanidade, como um semelhante:

É estranho ver estes nossos inimigos tão de perto. (...) são rostos bonachões de bons camponeses, testas largas, narizes largos, lábios grossos, mãos grandes e cabelos crespos. É gente para arar a terra e ceifar e colher maçãs. (REMARQUE, 1981, p. 154)

A posição pacifista do romance está clara nesta passagem:

\footnotetext{
${ }^{1}$ Essa visão romântica da guerra era compartilhada ainda no pós-guerra por muitos escritores alemães, como assinala Benjamin, em sua crítica à coletânea Guerra e Guerreiros, de 1930, composta por textos de vários autores, todos eles ex-soldados da Primeira Guerra Mundial: "Essa atitude se torna mais inteligível quando se considera como a ideologia guerreira representada na coletânea está ultrapassada pelo desenvolvimento do armamentismo europeu. Os autores omitiram o fato de que a batalha de material, na qual alguns deles vislumbram a mais alta revelação da existência, coloca fora de circulação os miseráveis emblemas do heroísmo, que ocasionalmente sobreviveram à grande guerra." (BENJAMIN, 1994, p. 62)
} 
(6)

- Mas uma coisa eu gostaria de saber - teria havido guerra, se o Kaiser se tivesse oposto?

(...)

— Bem, talvez ele sozinho não fosse suficiente, mas bastaria que umas vinte ou trinta pessoas no mundo tivessem dito "não".

— É provável — admito —, mas eram justamente estas pessoas que queriam a guerra. (REMARQUE, 1981, p. 164)

A narrativa do romance é vertida quase totalmente em primeira pessoa e predominantemente num tempo presente verbal, lembrando um diário de guerra; não um diário comum, mas um que fosse sendo escrito simultaneamente aos acontecimentos. Por vezes, em lugar desse presente imediato, é usado um presente ligado ao hábito, quando, por exemplo, o protagonista descreve a vida no front. De fato, o livro teria nascido de anotações feitas pelo autor (o próprio Remarque lutou na Grande Guerra, quando foi ferido três vezes, uma delas gravemente) depois de seu retorno à vida civil. Já o narrador em primeira pessoa só sai de cena na última página, ponto em que, surpreendentemente, morre o protagonista, sendo esse o único episódio do livro narrado por um narrador onisciente de terceira pessoa, retomando, de certo modo, a voz do autor, que aparece no pequeno prólogo, antes do começo da narrativa.

Trata-se de um relato muito realista, na medida em que seu objeto, no que possui de chocante e terrível, o permite, mas não é realista no sentido de uma descrição detalhada e naturalista, mas antes no uso de elementos como a primeira pessoa e o tempo presente, em correspondência com uma realidade imediata e fluida. Essa experiência teria sido de tal forma impressionante, que sua rememoração pelo ato de narrar sempre se dá como algo presente e contíguo à consciência, como se estivesse acontecendo - ou ameaçasse acontecer, como sucede com um terrível pesadelo, no momento da narrativa. Desse modo, podemos afirmar que, de certa maneira, contar a experiência da guerra é também vivê-la de novo, o que explicaria o pavor latente e o silêncio dos que retornaram vivos do campo de batalha.

Esse presente da narrativa tem como um de seus efeitos o de reforçar a impressão de que linguagem e realidade, narrativa e história estão entrelaçados, e que se constituem reciprocamente. O sujeito, elemento indissociável de qualquer desses aspectos opostos, aparece estilhaçado, como o soldado anônimo que jaz morto, meio ereto sobre o cavalo de frisa, vítima das granadas e metralhadoras. Seu olhar é sem mediação, sem termo de comparação, por isso não é capaz de compreender o que vê, nem qual o seu papel nessa realidade. Ao estilhaçamento do sujeito, no nível do significante, corresponde, no significado, a destruição do mito do herói, herança da poesia épica e igualmente presente nas narrativas ligadas aos discursos ideológicos mencionados. Nesta guerra não há heróis; há apenas meninos com medo, homens-animais que só sabem fugir da morte:

Tornamo-nos animais selvagens. Não combatemos, defendemo-nos da destruição. Sabemos que não lançamos as granadas contra homens, mas contra a Morte, que nos persegue, com as mãos e capacetes. (REMARQUE, 1981, p. 96) 
Nesse cenário, a luta corpo a corpo não tinha lugar; quando saíam das trincheiras, os soldados corriam pelo campo, jogando granadas contra o inimigo. Os que eram encontrados ainda vivos eram mortos à baioneta. A experiência da guerra de trincheiras, que Benjamin classifica no tipo genérico de "guerra de material", não dá ensejo ao surgimento de heróis e suas glórias. $\mathrm{O}$ uso de artilharia pesada, o bombardeio aéreo, o perigo do gás venenoso, o constante zumbir das balas de fuzil a poucos centímetros do chão obrigavam os soldados a manterem-se abaixados e imóveis durante vários dias:

A frente é uma jaula, dentro da qual a gente tem de esperar nervosamente os acontecimentos. Estamos deitados sob a rede formada pelos arcos das granadas, e vivemos na tensão da incerteza. Acima de nós, paira a fatalidade. Quando vem um tiro, posso apenas esquivar-me e mais nada; não posso adivinhar exatamente onde vai cair, nem influir em sua trajetória. (REMARQUE, 1981, p. 86)

Benjamin, ao referir-se a essa geração de homens, traça um quadro imagético bastante semelhante ao apresentado por Remarque na passagem anterior. À ideia de um "arco", descrito pelas granadas sobre as cabeças dos soldados entrincheirados, corresponde, em Benjamin, à abóbada celeste, a pairar sobre eles como um grande capacete. Além disso, a mesma impotência, a mesma insignificância do indivíduo, a quem só cabe esconder-se e esperar:

Uma geração que ainda fora à escola num bonde puxado por cavalos se encontrou ao ar livre em uma paisagem em que nada permanecera inalterado, exceto as nuvens, e debaixo delas, num campo de forças de torrentes e explosões, o frágil e minúsculo corpo humano. (BENJAMIN, 1994, p. 198)

A ideia relacionada à paisagem mencionada por Benjamin nesse trecho corresponde, ao que tudo indica, ao que ele denomina a "mobilização total da paisagem", enquanto resultado da guerra de trincheira que a tudo sob os céus altera e destrói. A consequência desse processo, ele definiu como "uma intensificação inesperada" do sentimento alemão pela natureza:

Os gênios da paz, que a habitavam tão sensoriamente, foram evacuados, e tão longe quanto nosso olhar podia ir além dos cemitérios, toda a região circundante tinha se transformado em terreno do idealismo alemão, cada cratera produzida pela explosão de uma granada se convertera num problema, cada emaranhado de arame construído para deter a progressão do inimigo se convertera numa antinomia, cada farpa de ferro se convertera numa definição, cada explosão se convertera numa tese, com o céu, durante o dia, representando o forro cósmico do capacete de aço e, de noite, a lei moral sobre nós. Com lança-chamas e trincheiras, a técnica tentou realçar os traços heroicos no rosto do idealismo alemão. Foi um equívoco. Porque os traços que ela julgava serem heroicos eram na verdade traços hipocráticos, os traços da morte. (BENJAMIN, 1994, p. 69-70)

A geração de homens que lutou na Primeira Guerra se perdeu; ao regressar para o seu país, depois do conflito, os ex-soldados descobririam que não tinham mais para o que 
voltar. Quando, durante a guerra, Paul vai a casa por alguns dias, de licença, ele mantém-se em silêncio sobre os acontecimentos do campo de batalha. Além disso, irrita-o a volubilidade com que a população civil encara a guerra. No meio da agitação de sentimentos e impressões, brilha acesa a chama da camaradagem dos companheiros que deixara no front, a "melhor coisa que a guerra produziu", como refere o protagonista (REMARQUE, 1981, p. 28). Toma-o um desejo de voltar logo para junto daqueles homens com quem compartilha a sorte. Esse silêncio dos combatentes é identificado por Benjamin:

\section{(11)}

No final da guerra, observou-se que os combatentes voltavam mudos do campo de batalha não mais ricos, e sim mais pobres em experiência comunicável... (BENJAMIN, 1994, p. 198)

Em seu famoso artigo de 1936, ${ }^{2}$ Benjamin identificou uma realidade que rotulou como "quase cotidiana": aquela de que "a arte de narrar está em vias de extinção", para falar de uma incapacidade de narrar que permeava a sociedade alemã de seu tempo (e que, sob tais aspectos, é ainda o nosso), de modo a concluir que o narrador nato era já então uma figura ausente na literatura e na cultura ocidental. $O$ crítico e filósofo alemão afirmava: "são cada vez mais raras as pessoas que sabem narrar devidamente" (BENJAMIN, 1994, p. 197).

A incapacidade de narrar se deve, segundo Benjamin, ao decréscimo do hábito cultural de transmitir a experiência coletiva de geração a geração, uso ligado à tradição oral. Dessa fonte primitiva é que deriva a narrativa em sentido estrito, categoria em que ele inclui a saga, a lenda e os contos de fada, e mesmo a novela, além de parte da poesia épica, como meio de ensinamentos, conselhos e de transmissão de cultura. Essa mudança de hábito coincide com a difusão do romance no início do período moderno, forma que ele situa em oposição à narrativa. Segundo Benjamin, não há no romance um narrador nato; ele "não procede da tradição oral nem a alimenta", o que acontece no caso da narrativa (BENJAMIN, 1994, p. 201). A narrativa, como a define, é mobilizada pela memória (quem ouve uma narrativa ouve porque quer repeti-la a outra pessoa) e caracteriza-se pela possibilidade de sempre poder continuar a história, mesmo depois de seu final (BENJAMIN, p. 210212).

Já o romance origina-se no indivíduo isolado, que não pode mais falar exemplarmente de suas preocupações e que não recebe conselhos, nem sabe dá-los (BENJAMIN, p. 201). Ele é movido pela rememoração, que o autor define, citando Lukács, como "uma reminiscência criadora, que atinge seu objeto e o transforma". Além disso, se a narrativa enraíza-se no coletivo, em "muitos fatos difusos", pois está integrada no curso da história e da cultura, com vistas a uma continuidade no curso das coisas, o romance, em virtude de uma visão fragmentada, parte de motivos particulares ('um herói, um combate'), buscando a uma totalidade e um fechamento. É assim uma forma fechada, no sentido de que, ao seu término, não há como continuá-lo. Conforme Benjamin, "a memória perpetuadora do romance" contrasta com "a breve memória do narrador". Se a narrativa caracteriza-se por finalizar com uma "moral da história”, quase nunca explícita, o romance encena a perplexi-

\footnotetext{
${ }^{2}$ O narrador. Considerações sobre a obra de Nikolai Leskov, artigo de 1936, em Obras escolhidas, vol. 1, 7.
} ed. 
dade existencial: no final de cada romance, fica uma pergunta sobre o "sentido da vida" (BENJAMIN, p. 210-212).

O desprestígio da experiência (entendida como experiência coletiva) na sociedade ocidental fundou a crise do narrador, de que o romance, segundo Benjamin, é o primeiro indício (BENJAMIN, p. 201). Por certo, tal fenômeno não se deu simplesmente por opção dos indivíduos. As mudanças que atingiram o Ocidente no início do século XX (e especialmente a Alemanha derrotada), num cenário de dificuldades econômicas, com o fortalecimento dos regimes fascistas, que apelavam à beligerância dos povos (como estratégia evasiva às insatisfações populares), junto a um avanço tecnológico que, sem aplicação "completa e adequada" em outras áreas da vida social, acabou direcionado para a indústria béli$\mathrm{ca}^{3}{ }^{3}$ levaram a experiências como a guerra de trincheiras, que, entre outras, marca a passagem para esse outro período da humanidade, quando o sujeito encontra-se segregado e só numa paisagem destruída, definitivamente apartado de seu meio natural e social:

Porque nunca houve experiências mais radicalmente desmoralizadas que a experiência estratégica pela guerra de trincheiras, a experiência econômica pela inflação, a experiência do corpo pela guerra de material e a experiência ética pelos governantes. (BENJAMIN, 1994, p. 198)

A incapacidade de narrar, nos termos de Benjamin, é, portanto, característica constitutiva do romance, e não implica a ausência de enredo ou história (nem mesmo de um narrador, em sentido lato). Trata-se do fim de um certo tipo de narrador e de narrativa, e do surgimento, quase simultâneo, de outro. O que interessa discutir, entretanto, é se e como essa incapacidade se manifesta em Nada de novo no front, caso em que nos interessa também a estratégia, por assim dizer, de mimese adotada no romance. Além disso, interessa secundariamente verificar se, em que medida e por quais aspectos a narrativa de guerra, de modo geral, pode ser considerada um gênero literário, ou se, ao menos, algumas de suas características permitem ou determinam uma leitura diferenciada.

Neste ponto é que será útil a teoria da enunciação de Benveniste, cujos pontos que aqui interessam vamos agora expor brevemente.

O linguista francês Émile Benveniste, ao formular a ideia de enunciação, a que definiu como um "colocar em funcionamento a língua", através de "um ato individual de utilização" (BENVENISTE, 1989, p. 82), e ao proferir o seu enunciado basilar — o de que 'a subjetividade está na língua' (BENVENISTE, 1991, p. 286 e 288), estabeleceu um novo marco nos estudos linguísticos que, até então, ainda tinham como quase irretocáveis os pressupostos de Saussure, para quem o que importava no estudo da língua era o sistema de signos em sua virtualidade e não a língua em funcionamento, no momento preciso em que está sendo utilizada por um sujeito. De fato, a linguística saussuriana considerava secundário o exame da língua em seu uso concreto, que relegava à fala, domínio do fortuito, e privilegiava o estudo da língua enquanto sistema, com destaque para a ideia da arbitrariedade

\footnotetext{
3 “A guerra e somente a guerra permite dar um objetivo aos grandes movimentos de massa, preservando as relações de produção existentes. Eis como o fenômeno pode ser formulado do ponto de vista político. Do ponto de vista técnico, sua formulação é a seguinte: somente a guerra pode mobilizar em sua totalidade os meios técnicos do presente, preservando as atuais relações de produção.” (BENJAMIN, 1994, p. 195)
} 
do signo linguístico e para o conceito de valor. O objetivo de Benveniste foi dar continuidade à teoria saussuriana do ponto em que o linguista suíço tinha parado; em suas palavras, seu propósito foi ultrapassar Saussure, com o estabelecimento em bases sólidas de uma teoria que desse conta não só da língua enquanto sistema, do campo do semiótico, mas também da língua em seu uso concreto, do campo do semântico ${ }^{4}$ É sintomática dessa posição a crítica dirigida à tese do arbitrário do signo saussuriano, a par da importância atribuída ao conceito de valor. Na fase final de sua obra, ele formulou a tese do aparelho formal da enunciação, quando buscou determinar os elementos formais da língua em processo.

No estudo que fez da pessoa verbal e dos pronomes pessoais, Benveniste identificou o que denominou os signos "vazios" do sistema da língua, ou "indicadores", palavras como "eu” e "tu”, "aqui”, "agora", as quais são "preenchidas" no ato da enunciação. Segundo ele, são essas palavras as marcas da subjetividade na língua, pois só ganham significação quando um indivíduo resolve se utilizar da língua, pondo-a em funcionamento. Orientam-se a partir de um centro "gerador e axial" — o "eu", que organiza o discurso no espaço e no tempo. O "eu" (ego) é ponto de referência e centro organizador da língua em processo. Junto a um aqui-agora espacial, determina o tempo linguístico, definido por Benveniste como o eterno presente do discurso, e que equivale ao 'tempo em que se fala'. Para o linguista francês, a introdução da pessoa no discurso, através do preenchimento da posição "eu", instaura a experiência humana e a subjetividade através da língua. Aquele que fala se "apropria" da forma vazia de "eu", preenchendo-a no ato de enunciação, evocando um "tu" e um "ele" (BENVENISTE, 1989, cap. 4, p. 69) e instituindo a partir daí o que definiu como a intersubjetividade na língua. Para Benveniste, o "eu" e o "tu" são as únicas verdadeiras formas de pessoa da língua, sendo o "ele" definido como a "não-pessoa" (BENVENISTE, 1991, cap. 18, p. 255).

Da teoria de Benveniste, destacamos dois de seus fundamentos principais: 1) o lugar da subjetividade na língua enquanto instauradora da experiência humana; e 2) o tempo linguístico, o presente cujo ponto de referência é o "eu" do discurso. O primeiro determina que o indivíduo, ao ingressar na linguagem, mobiliza uma rede social, tomando o lugar que lhe é reservado nela. Contudo, sendo a linguagem uma instituição social, o lugar que o sujeito ocupa na língua e a experiência que instaura também são socialmente determinados. Nesse sentido - o de instaurar uma experiência do real através da língua, é que, em Benveniste, podemos afirmar que o dizer é fazer ${ }^{5}$, mas fazer na linguagem. Já o presente linguístico é o tempo da enunciação e assinala a subjetividade no discurso. Marca também a maior proximidade com real, a posição mais imediata.

O relato de Nada de novo no front, como já referido, é quase todo em primeira pessoa, alternando-se, de resto, entre um "eu" e um "nós". Quanto ao tempo, predomina o presente da enunciação, que se alterna com um presente habitual e que coincide com a narra-

\footnotetext{
${ }^{4}$ Na primeira fase de sua obra, Benveniste cria a distinção entre o campo semiótico, referente ao sistema da língua em sua virtualidade, e o campo semântico, referente à língua em seu uso concreto no discurso.

${ }^{5}$ E não no sentido bem mais estrito que dá a esse enunciado o filósofo inglês Austin (John Langshaw Austin, 1911-1960), com sua teoria dos atos performativos, publicada postumamente na obra intitulada How to do things with words (1962), título em português: Quando dizer é fazer — palavras e ação. Para este, dizer é fazer na realidade, e não somente na linguagem, como a expressão "eu condeno", dita por quem tem autoridade para condenar, não apenas expressa, mas também realiza o ato de condenar. Entretanto, são casos específicos. Essa teoria também é abordada por Benveniste.
} 
ção em primeira pessoa (a passagem para a terceira pessoa, no final do romance, marca também a mudança de tempo da narração para o passado).

$\mathrm{O}$ uso da primeira pessoa, conjugado com o presente, cria uma atmosfera realista e de proximidade com o real contado. O eu que diz "eu" também vive o que narra, no momento em que narra, o que dá ao narrado um caráter imediato e, num sentido específico, realista (ver p. 49, acima). O dizer da enunciação não é o real (a não ser que seja tomado como um real linguístico), mas é um dos poucos modos de atingir o ponto mais próximo possível daquele real a que o pensamento logra chegar. Mas o ponto que atinge trata-se, a princípio, do real do dizer e não de qualquer real.

O que Remarque consegue, neste romance, é um efeito de realismo baseado na combinação dos dois aspectos, fazendo com que o real do dizer coincida com o real narrado, através do emprego da primeira pessoa e do tempo presente. $\mathrm{O}$ que deve ser acrescentado é que essa estratégia de mimese procura responder (e creio que com bons resultados) às exigências da obra e do tema, diante da incapacidade de contar histórias — de resto uma característica típica do narrador de romance, mas também em razão da própria experiência narrada - a guerra, e a resistência que oferece ao olhar (a sua face chocante). A presença desse "eu" chega a emergir à superfície do texto, nas últimas palavras do narrador em primeira pessoa:

(...) A vida, que me arrastou por todos estes anos, eu ainda a tenho nas mãos e nos olhos. Se a venci, não sei. Mas enquanto existir dentro de mim - queira ou não esta força que em mim reside e que se chama "Eu" - ela procurará seu próprio caminho. (REMARQUE, 1981, p. 231)

Esse mesmo dizer é fazer corresponde, em um aspecto essencial, à definição de Benjamin para a narrativa, a saber, a de constituir uma experiência socialmente determinada. Na narrativa, o narrador conta a sua experiência, que se insere na experiência mais ampla da coletividade e com isso enriquece a experiência do ouvinte ou leitor. Este, por sua vez, está também inserido na coletividade, e aceita a missão de reproduzir a narrativa, sustentando uma espécie de corrente ao infinito. De fato, esse narrador, ao contar sua história, ingressa numa rede, mobilizada pela linguagem. A "moral da história" muitas vezes encerra um sentido profundo, mas não quer abarcar a totalidade do real, pois o sujeito aqui está integrado em sua realidade e não sente essa necessidade. Com o rompimento dessa tradição cultural, que foi assinalada, segundo Benjamin, pelo aparecimento do romance, o narrador já não quer comunicar sua experiência, nem o leitor quer aprender algo que vai transmitir a outrem.

Há aqui um desejo sôfrego de abarcar a totalidade do real e por isso a pergunta sobre o "sentido da vida", nunca respondida. As experiências contadas pelo narrador do romance, assim como a vida do leitor, são humilhantes. Não há aprendizado possível nelas. O sujeito aqui está apartado de sua realidade. Tudo o que restava de seu mundo foi destruído, no que a cena do campo minado e do front destruído pelas bombas, em Nada de novo no front, são imagens perfeitas. A tradição, o passado, nada ficou de pé; nem os cemitérios. Toda a memória foi estilhaçada. O sentimento de desagregação e segregação põe no primeiro plano o indivíduo solitário, quase sem memória cultural. Perto de ser uma tábula rasa, o jovem e inexperiente Paul Bäumer, junto com seus companheiros de mesma idade, só sabe 
que precisa 'livrar-se de toda esta embrulhada'; em outras palavras, sobreviver. Não há lealdade aos ideais da guerra, de tudo desacreditaram; apenas a disciplina militar - e a camaradagem aos companheiros, os impelem para a frente. A morte, porém, os persegue, e um a um, vão todos sendo mortos, até o último, que é o próprio Paul. O destino do herói do romance é assim cumprido pelo protagonista. Sua morte acende no leitor a pergunta sobre o sentido de sua vida. Entretanto, assim como os mortos habitam a nossa lembrança, o final do romance revive Bäumer para nós, quando um impessoal narrador em terceira pessoa conta a sua morte anônima e vira para o céu de nuvens inalteradas o seu rosto insignificante. A morte do herói faz voltar-se o olhar para a sua vida. A estupefação do leitor reside em perceber que dele não ficou nenhuma herança para a posteridade:

Tombou morto em outubro de 1918, num dia tão tranquilo em toda a linha de frente, que o comunicado limitou-se a uma frase: "Nada de novo no front".

Caiu de bruços, e ficou estendido, como se estivesse dormindo. Quando alguém o virou, viu-se que ele não devia ter sofrido muito. (REMARQUE, 1981, p. 231)

Do mesmo modo que a relação entre linguagem e experiência humana, feita por Benveniste, transposta aqui na expressão um tanto problemática do dizer é fazer, embora com as ressalvas indicadas, ajuda a elucidar as diferenças entre a narrativa (no sentido estrito que lhe dá Benjamin) e o romance, também ajuda a compreender a estratégia de mimese do livro de Remarque. O realismo da narração em Nada de novo no front é conferido pela presença constante de uma subjetividade, que se dá a conhecer numa linguagem nua, através da qual, sem hesitar, revela seu espanto diante do absurdo da guerra. Não se trata da imanência da linguagem, mas da linguagem onde habita o sujeito e a sua experiência, por mais humilhante que seja. Porém, não mais o sujeito integrado no seu mundo, mas aquele que o perdeu para sempre. Por outro lado, a rigor, não faltaria experiência na modernidade, o que se pode pensar a partir do que foi dito aqui: haveria nela experiência, mas outra forma de experiência, compreendendo sua própria incomunicabilidade, aliada à segregação do sujeito que determina. A aparição da terceira pessoa, logo após a morte do "eu" que narra, além de uma estratégia para manter a verossimilhança da narração, ao traçar uma moldura externa ao discurso do narrador-protagonista, marca um novo distanciamento. O distanciamento é inerente à ironia final que, diante do fim trágico do herói, se manifesta em expressões como o "dia tranquilo" em que nada de novo acontecera no front, a aparência de que estava dormindo e, como fecho, a declaração descompromissada de "que não devia ter sofrido muito".

A incapacidade de narrar, no contexto em que a situa Benjamin, a par da dificuldade específica de contar a guerra, com a estratégia de superação dessa dificuldade, está na base da concepção do romance de Remarque. A mimese realista supera a dificuldade específica, mas não subverte as características da forma. O protagonista de Nada de novo no front é ainda uma personagem típica de romance, mas ao final da leitura vemos que nada sobrou da idealização romântica do herói. De outro modo, se podemos falar de um gênero de literatura de guerra, certamente a solução que apresenta é válida. O olhar quase sem mediação, icônico, deriva de seu próprio objeto. Além disso, seu pacifismo é profundamente humano, principalmente se consideramos que é o ponto de vista do vencido: a perenidade 
da obra procede em grande parte da humanidade com que são apresentadas as personagens, inclusive os inimigos.

\section{REFERÊNCIAS}

BENJAMIN, Walter. Magia e técnica, arte e política: ensaios sobre literatura e história da cultura. Trad. Sérgio Paulo Rouanet. 7. ed. São Paulo: Brasiliense, 1994. (Obras escolhidas, v. 1)

BENVENISTE, Émile. Problemas de linguística geral I. Trad. Maria da Glória Novak \& Maria Luiza Neri. Campinas: Pontes; Editora da Unicamp, 1991.

BENVENISTE, Émile. Problemas de linguística geral II. Trad. Eduardo Guimarães |et al.|. Campinas: Pontes, 1989.

REMARQUE, Erich Maria. Nada de novo no front. Trad. Helen Rumjanek. São Paulo: Abril Cultural, 1981.

Recebido em: 17/05/2015

Aceito em: 16/06/2015

${ }^{\text {i }}$ Doutor em Letras pela Universidade Federal do Rio Grande do Sul. Email: pedro.santos@ufrgs.br. 